\title{
A POLÍTICA DO PRECARIADO'
}

\author{
José Guirado Netoa
}

O interesse em escrever A política do precariado: do populismo à hegemonia lulista surgiu durante o ano de 2008, quando Ruy Braga estava à frente do Centro de Estudos dos Direitos da Cidadania da Universidade de São Paulo (CENEDIC/USP). André Singer, já há alguns anos, havia trazido a discussão acerca do "lulismo" para o interior do grupo, quando, na época, Chico de Oliveira chamou a atenção dos participantes para a importância de investigar as origens da forma de hegemonia que se instalara no Brasil a partir do governo Lula. Diante das inquietações suscitadas por esse debate, Ruy delimitou o fio condutor de seu projeto de pós-doutorado, que mais tarde daria origem à obra A política do precariado, a saber: analisar criticamente o populismo fordista até o "lulismo" hegemônico atual, sob a ótica da política do precariado. Para dar conta de tal empreitada, o autor resgatou o arcabouço teórico da sociologia marxista e da sociologia pública (de Michael Burawoy) que já carregava em sua bagagem intelectual, como em $A$ nostalgia do fordismo (2003) e Por uma sociologia pública (2009).

A obra parte de um diálogo crítico tecido com diversos textos consagrados da sociologia do trabalho brasileira, de autores como Juarez Lopes, Leôncio Rodrigues, Jonh Humphrey e Ricardo Antunes (só para mencionar alguns). Por essa via, o livro segue em tom inovador, ao abordar a formação e a transformação da política do precariado brasileiro, por meio da teoria da inquietação operária. Assim, o autor pretende desmistificar (e é bem-sucedido) a suposta passividade política do precariado, ao longo do período analisado (1950-2012), ainda que a organização político-social desse grupo apresentasse características divergentes e flutuantes ao longo dos anos destacados.

Já na introdução, Braga (2012, p. 18) define aquilo que entende como precariado: "Aos nossos olhos, o precariado, isto é, o proletariado precarizado, é formado por aquilo que, excluídos tanto o lupemproletariado quanto a população pauperizada, Marx chamou de ‘superpopulação relativa'”. Além disso, complementa:

1 Braga, Ruy. A política do precariado: do populismo à hegemonia lulista. São Paulo: Boitempo, 2012.

a Mestrando do Programa de Pós-Graduação em Sociologia da Universidade de São Paulo (PPGS/ USP). 
A necessidade de definir os limites gerais do precariado nos obriga também a diferenciá-los dos setores profissionais, ou seja, aqueles grupos mais qualificados, mais remunerados e, por isso mesmo, tendencialmente mais estáveis, da classe trabalhadora. Em suma, identificamos o precariado com a fração mais mal paga e explorada do proletariado urbano e dos trabalhadores agrícolas (BRAGA, 2012, p. 19).

Desse modo, o recorte teórico que corresponderia ao precariado seria composto pela população flutuante, latente e estagnada (em relação ao mercado de trabalho), que possuiria renda entre, aproximadamente, um e dois salários-mínimos e que, sem sombra de dúvida, possuiria significativa capacidade de mobilização coletiva - o que, aliás, é salientado ao longo da obra, mediante exemplos histórico-sociais ${ }^{1}$.

O primeiro capítulo, intitulado "O espectro do povo", trata da formação da chamada "nova classe operária”, no período entre 1950 e 1970, e de como a sociologia profissional lidou com essa problemática. Inicialmente, o autor relata que os fundamentos ideológicos da sociologia que se debruçou sobre a questão do trabalho nas décadas de 1950 e 1960 giraram em torno do "desafio da modernização da periferia capitalista"; ou seja, a questão do "atraso" brasileiro teria condicionado as principais análises sociológicas da época, sobretudo aquelas que trataram da classe operária. Ruy toma, então, como exemplo as pesquisas de Rodrigues (1966), em Conflito industrial e sindicalismo no Brasil, e entende que o autor, ao se ocupar do movimento sindical durante a consolidação do fordismo periférico, estaria, na verdade, perseguindo um dos principais objetivos definidos pelo CESIT $^{2}$ : investigar a relação entre a mobilização da força de trabalho com a modernização industrial brasileira.

Isso posto, Leôncio Rodrigues entenderia que os robustos fluxos migratórios do campo em direção às cidades brasileiras, durante a metade do século XX, seriam resultado da perspectiva, por parte dos trabalhadores, de ganho de direitos sociais.

1 Se Robert Castel (2006) afirma que a precariedade parece estar se transformando em um "registro regular da organização do trabalho", ameaçando décadas de institucionalização de direitos sociais nos países capitalistas avançados, para Braga (2012), a precariedade nunca teria deixado de ser a regra na periferia do sistema.

2 É interessante o mapeamento histórico realizado pelo autor acerca do surgimento do Centro de Estudos da Sociologia Industrial e do Trabalho (CESIT) em 1962 - "laboratório sociológico" de renome nacional que contava com nomes como o de Florestan Fernandes, Fernando Henrique Cardoso, Leôncio Martins Rodrigues, Lourdes Sola, Celso Beisiguel, Gabriel Bolaffi e José Carlos Pereira. O CESIT nasceu de uma agenda de pesquisas das bases do subdesenvolvimento brasileiro, e seus três principais eixos de investigação eram: i) a mentalidade do empresário; ii) o papel do Estado no desenvolvimento; e iii) as características da mobilização da força de trabalho no processo de modernização capitalista. 
Nesse contexto, o jovem precariado industrial parecia não se interessar em absoluto pela política nacional, tampouco pelos conflitos industriais que o atingiam diretamente. Em suma, a ideia é de que, durante a vigência do populismo, o ainda jovem precariado brasileiro teria atuado como massa de manobra dos setores trabalhistas e comunistas.

Ruy afasta essa ideia e defende a hipótese alternativa de que a somatória de promessas não cumpridas pelo modelo de desenvolvimento com o despotismo do regime de acumulação fez com que o fordismo periférico, em vez de promover um suposto consentimento ou uma passividade, tenha provocado, no caso brasileiro, uma inquietação operária que resultou em organizações de greves, mobilizações de bairros, pressão sobre as lideranças sindicais, participação coordenada em eleições, etc. Para tanto, Braga encontra elementos em diversas fontes, como, por exemplo, na obra de Jorge Miglioli (1963), Como sãofeitas as greves no Brasil?, que investiga uma mesma passagem histórica que Rodrigues - as greves na indústria paulistana - e encontra conclusões divergentes do último.

Ainda nesse capítulo, o autor resgata os estudos de Juarez Lopes acerca de duas indústrias têxteis de Minas Gerais das cidades de "Sobrado" e "Mundo Novo"3 e da metalúrgica paulistana Metal Leve. Diz Braga (2012) que, assim como Rodrigues, Lopes também teria ressaltado "o contraste entre as distintas realidades sociais, capitalista avançada e subdesenvolvida" e seu papel para a pesquisa sociológica brasileira. Com efeito, a preocupação da sociologia profissional do trabalho era conseguir articular teoricamente o regime de acumulação despótico ao modo de regulação populista. Para Ruy (2012), as duas pesquisas realizadas por Lopes apresentam o mesmo problema sociológico: “o bloqueio da ação política classista devido à influência de padrões, valores e relações patrimonialistas de poder sobre o comportamento do precariado fabril" (p. 73) e, assim, a "resiliência do passado rural brasileiro interporia obstáculos insuperáveis ao desenvolvimento da consciência operária” (p. 73). Todavia, o autor de A política do precariado encontra vestígios contrários a tal tese na própria etnografia realizada por Juarez Lopes.

Quanto ao segundo capítulo, o foco recai mais sobre a reconstrução teórica da ciência do classismo prático, utilizando os trabalhos de José Albertino Rodrigues, Francisco Welfort, Luiz Pereira e Chico de Oliveira, com destaque especial para as análises de Michael Burawoy. Nesse momento, são analisados a dinâmica do populismo e o surgimento do ciclo de greves do final dos anos 70 do século XX. A principal hipótese considerada é a de que, a partir da investigação da formação

3 Nomes de municípios fictícios utilizados por Juarez Lopes. 
e transformação da política do precariado brasileiro e por meio da reconstrução teórica da sociologia da inquietação operária, é possível concluir que “o fordismo periférico frustrou as principais expectativas despertadas pela promessa de superação do subdesenvolvimento" (BRAGA, 2012, p. 35). Isso teria se desenrolado, sobretudo, devido aos "limites impostos ao modo de regulação pela inserção dependente da estrutura econômica do país na divisão internacional do trabalho" (BRAGA, 2012, p. 35).

O título desse capítulo, "O fatalismo dos fracos”, merece algumas considerações. Ruy (2012, p. 108) constata:

Ao contrário de Leôncio Rodrigues, para quem a fragilidade do movimento sindical das primeiras décadas do século XX teria permitido ao Estado Novo tutelar a classe operária por meio da CLT, Albertino Rodrigues entendia que a combatividade operária de 1930 havia influenciado a promulgação das leis trabalhistas.

\section{E segue:}

Enquanto Martins Rodrigues afirmou que as greves de 1953, 1954 e 1957 demonstravam a incapacidade dos sindicatos de se enraizarem no precariado migrante, Alberto Rodrigues entendia que esse ciclo grevista, além de garantir resultados práticos em termos salariais, fortaleceu o sindicalismo no país (BRAGA, 2012, p. 111).

Nota-se, nessas passagens, a tendência da sociologia profissional em atribuir um papel coadjuvante e passivo ao operariado precarizado. No entanto, ao resgatar a expressão "fatalismo dos fracos" dos Cadernos do Cárcere de Antônio Gramsci (1999), Ruy parece querer fazer suas as palavras do comunista sardo e, assim, dar resposta clara à sociologia profissional brasileira:

No fundo, se o subalterno era ontem uma coisa, hoje não mais o é: tornou-se uma pessoa histórica, um protagonista; se ontem era irresponsável, já que era "resistente" a uma vontade estranha, hoje se sente responsável, já que não é mais resistente, mas sim agente e necessariamente ativo e empreendedor. Mas, mesmo ontem, será que ele era simples "resistência", simples "coisa", simples "irresponsabilidade"? Não, por certo; deve-se, aliás, sublinhar que o fatalismo não é senão a maneira pela qual os fracos se revestem de uma vontade ativa e real (Gramsci, 1999, p. 106-107). 
No terceiro capítulo, "O sorriso dos explorados", a ideia predominante é a de que o jovem precariado migrante teria se transformado em vigorosa força política capaz de reconfigurar o movimento sindical brasileiro, além de contribuir para a queda do regime militar. Para sustentar sua visão, fundamenta-se nas greves de Contagem e Osasco, em 1968, e, principalmente, nas greves que se sucederam, até a tomada da Ford de São Bernardo do Campo, em 1981. Nesse embalo, o capítulo procura delimitar, por meio de uma reconstrução etnográfica, a relação entre burocracia sindical (destaque para a de São Bernardo), a política metalúrgica do precariado e a formação do novo sindicalismo.

Braga busca no ativismo das bases e no poder sindical o que chama de "arqueologia da hegemonia lulista". Por mais que o autor acredite que o PT tenha nascido carente de uma hegemonia determinada, para ele, nos ciclos grevistas sob o comando sindical de São Bernardo, as raízes do que no futuro tornar-se-ia a dominação hegemônica "lulista" já se faziam presentes. Diz ele: "após o contratempo eleitoral de 1982, diversas lideranças que gravitavam em torno de Lula da Silva decidiram formar uma corrente interna conhecida de 'Articulação"' (BRAGA, 2012, p. 36). Essa, por sua vez, "foi a primeira tentativa bem-sucedida de construir a hegemonia lulista para além da estrita relação entre os sindicalistas e suas bases" (BRAGA, 2012, p. 36).

Assim, no quarto e último capítulo, "A angústia dos subalternos", é realizado um estudo de caso da indústria paulistana de call center. A escolha desse recorte se deve ao fato de que esse setor teria se demonstrado um terreno privilegiado de observação das transformações mais recentes que o precariado teria sofrido e, ao mesmo tempo, ainda reuniria as principais tendências do mercado de trabalho do país nos últimos decênios, tais como: formalização, aumento do contingente feminino no quadro das empresas, baixos salários, terceirização, incorporação de jovens pardos e negros e alta taxa de rotatividade do trabalho.

No desenrolar do capítulo, nota-se um entrelace interessante entre a hegemonia "lulista" e o sindicalismo brasileiro como um todo. A ideia defendida é a de que o "lulismo", ao incorporar sindicalistas em diversos cargos superiores de direção, teria influenciado uma "reviravolta transformista" nas relações entre o sindicalismo brasileiro e o aparelho de estado. No caso dos teleoperadores, essa problemática mais ampla irá lançar luz sobre as mudanças ocorridas nos sindicatos que atuam na indústria paulistana de call center. O autor constatou, por exemplo, que, nas entrevistas realizadas, a posição dos dirigentes sindicais e ativistas de 
base do Sintetel e Sintratel (sindicatos vinculados ao setor do call center), em especial com relação ao governo Lula, era amplamente favorável.

Ainda assim, a despeito das dificuldades de mobilização coletivas, desde 2005, greves vêm ocorrendo no setor de telemarketing paulistano com certa frequência. Diante desse e de outros fatos apresentados, BragA (2012, p. 212) previu que começaria a se "formar um embrião de consciência coletiva, forte o suficiente para garantir alguns passos importantes no caminho da auto-organizacao sindical".

A amarração entre a pesquisa de campo e a teoria sociológica empreendidas por Ruy Braga (2012, p. 37) no capítulo final convida o leitor a refletir sobre a "dialética lulista", que, em suas palavras,

combina o consentimento passivo das massas - que, seduzidas pelas políticas públicas redistributivas e pelos modestos ganhos salariais advindos do crescimento econômico, aderiram ao governo - com o consentimento ativo das lideranças sindicais - seduzidas, por sua vez, por posição no aparato estatal, fora as incontáveis vantagens materiais proporcionadas pelo controle dos fundos de pensão ${ }^{4}$.

Talvez devêssemos apontar dois momentos da obra que podem gerar algum desconforto nos leitores mais críticos: o primeiro é quanto à discussão da ressignificação do conceito de precariado realizada pelo autor; o segundo é referente ao vácuo histórico de quase duas décadas que a obra apresenta. Não há crença, aqui, de que a interpretação do precariado empregada por Ruy Braga seja um problema em si - até porque seu emprego parece pertinente. No entanto, por se tratar de uma questão polêmica que divide os pesquisadores da área, essa questão poderia ter sido desenvolvida mais extensamente, pois no livro apenas algumas páginas da introdução são dedicadas ao assunto. Quanto ao segundo ponto - e esse sim, provavelmente, mais relevante -, nota-se que a obra praticamente não aborda o período que segue entre o início da década de 1980 e os anos 2000, recorte temporal igualmente importante devido à maturação do Partido dos Trabalhadores e à própria escalada da hegemonia "lulista" - o que, de fato, é reconhecido pelo autor.

4 Braga faz, aliás, um balanço geral sobre a relação entre sindicalismo e a hegemonia "lulista": "O resultado do encontro de demandas repassadas dos movimentos sociais como "transformismo sindical' promovido pelo lulismo representou, sem dúvida, um incremento da tutela do movimento sindical de base pelo aparelho do Estado" e, portanto, "por intermédio desse tipo de transformismo, o governo Lula conseguiu coroar a incorporação de parte das reivindicações 'debaixo' com a bem orquestrada reação à subversidade esporádica dos subalternos” (BRAGA, 2012, p. 177). 
Em síntese, A política do precariado traz indubitável contribuição ao entendimento da formação e ao desenvolvimento do precariado brasileiro, desde a década de 1950 até a contemporaneidade. O texto demonstra vigor crítico-analítico acerca do precariado, em um contexto-chave: o de crise econômica em diversos países centrais do capitalismo, em que as diversas conquistas históricas dos trabalhadores procuram ser combatidas como forma de reduzir sistematicamente o custo da força de trabalho.

\section{REFERÊNCIAS BIBLIOGRÁFICAS}

BRAGA, Ruy. A nostalgia do fordismo. São Paulo: Xamã, 2003.

A política do precariado: do populismo à hegemonia lulista. São Paulo: Boitempo, 2012.

Braga, Ruy; Burawoy, Michael (Org.) Por uma sociologia pública. São Paulo: Alameda, 2009.

CASTEL, Robert. Et maintenant, le “precariat”. Le Monde, 29 abr. 2006.

Gramsci, Antônio. Cadernos do cárcere. v. 1. Rio de Janeiro: Civilização Brasileira, 1999. Miglioli, Jorge. Como são feitas as greves no Brasil? São Paulo: Civilização Brasileira, 1963.

Rodrigues, Leôncio. Conflito industrial e sindicalismo no Brasil. São Paulo: Difusão Europeia do Livro, 1966.

Recebido para publicação em 20/04/2013. Aceito para publicação em 20/05/2013. 
